\title{
Natural Killer Cell Regulation by MicroRNAs in Health and Disease
}

\author{
Jeffrey W. Leong, Ryan P. Sullivan, and Todd A. Fehniger \\ Division of Oncology, Department of Medicine, Washington University School of Medicine, 660 S Euclid Avenue, \\ Campus Box 8007, St. Louis, MO 63110, USA
}

Correspondence should be addressed to Todd A. Fehniger, tfehnige@wustl.edu

Received 10 August 2012; Accepted 12 September 2012

Academic Editor: Wolfgang Arthur Schulz

Copyright ( $\odot 2012$ Jeffrey W. Leong et al. This is an open access article distributed under the Creative Commons Attribution License, which permits unrestricted use, distribution, and reproduction in any medium, provided the original work is properly cited.

\begin{abstract}
Natural killer (NK) cells are innate immune lymphocytes that are critical for normal host defense against infections and mediate antitumor immune responses. MicroRNAs (miRNAs) are a family of small, noncoding RNAs that posttranscriptionally regulate the majority of cellular processes and pathways. Our understanding of how miRNAs regulate NK cells biology is limited, but recent studies have provided novel insight into their expression by NK cells, and how they contribute to the regulation of NK cell development, maturation, survival, and effector function. Here, we review the expression of miRNAs by NK cells, their contribution to cell intrinsic and extrinsic control of NK cell development and effector response, and their dysregulation in NK cell malignancies.
\end{abstract}

\section{Introduction}

NK cells are innate immune lymphocytes that are important for host defense against pathogens and exhibit antitumor responses [1-4]. They develop from progenitors in the bone marrow through a series of intermediates, which depend on growth factors and cytokines to support their development and peripheral homeostasis, especially IL-15 $[1,5,6]$. In humans, NK cells are identified as $\mathrm{CD} 56^{+} \mathrm{CD}^{-}$lymphocytes without rearranged $\mathrm{T}$ cell receptors and may be divided into developmentally and functionally distinct subsets based on the expression of CD56 and CD16 (Fc $\gamma$ RIIIa), CD56 $6^{\text {bright }}$ and CD56 ${ }^{\mathrm{dim}}$ [4]. In mice, NK cells are identified by the NK1.1 or NKp46 activating $\mathrm{NK}$ cell receptors in $\mathrm{CD}^{-} \mathrm{CD} 19^{-}$ lymphocytes [6]. NK cells undergo final steps of maturation in peripheral lymphoid organs, which can be marked by coexpression of CD27 and CD11b [7]. NK cells mediate several effector functions, including production of cytokines and chemokines, as well as cytotoxicity against appropriately recognized virus-infected and tumor target cells [8]. NK cells recognize abnormal cells with loss of self markers detected by inhibitory receptors that recognize classical and nonclassical MHC class I molecules, which are subject to an education process that includes licensing $[9,10]$. NK cells are stimulated via activating NK cell receptors that bind to ligands expressed on infected, malignant, or stressed cells. The balance of activating and inhibitory receptor signaling determine whether NK cells are triggered by a potential target cell $[11,12]$. In addition, NK cells express a number of cytokine receptors and are activated by proinflammatory cytokines, which prime them for optimal effector function, and overcome some inhibitory based signals [4, 13-16]. Thus, NK cells have a unique biological program that is highly regulated and distinct from adaptive $\mathrm{T}$ and $\mathrm{B}$ lymphocytes. The molecular events and program that define NK cells are incompletely understood and remains a critical area of NK cell investigation.

The significance of NK cells to human health is highlighted by multiple patients with selective NK cell deficiency, who present with recurrent, often fatal herpesvirus infections early in life $[17,18]$. Such studies are complemented by a pediatric patient with $\mathrm{T}$ and $\mathrm{B}$ cell severe combined immunodeficiency (SCID) that mounted a potent NK cell response to human cytomegalovirus (CMV) [19], indicating 
that NK cells may provide host protection against viral pathogens in the absence of adaptive immunity. Such patients are rare, but highlight the importance of NK cells to human health. Further, numerous studies in mice have corroborated the importance of NK cells to host defense against many infectious pathogens, and have provided the mechanistic findings to better understand the contribution of NK cells to anti-microbial host defense [8, 20,21].

NK cells also respond to malignant tumor cells and represent an important immunotherapeutic effector for cancer, particularly hematologic malignancies [22-26]. In a large epidemiologic study, low NK cell function was associated with an increased risk of developing cancer [27]. The widespread use of monoclonal antibody therapy for cancers, especially lymphoma, depends on autologous antibodydependent cellular cytotoxicity mediated in part by NK cells [28]. Clear evidence of NK cell activity against cancer in patients arises from haploidentical stem cell transplantation [29] and adoptive NK cell therapy studies [30] in acute myeloid leukemia (AML). These studies directly link an allogeneic NK cell anti-AML response, controlled in part by NK receptors, to leukemia clearance and long-term survival for these patients. These reports underscore the significance and promise of NK cells as effectors against this disease, and potentially other malignancies. Moreover, these findings indicate that a better understanding of basic NK cell biology will inform future strategies to use NK cells as anticancer and infectious disease effector cells [23].

Currently, our understanding of the basic molecular mechanisms regulating NK cell development, maturation, survival, and function is incomplete. A number of transcription factors have been identified that contribute to key aspects of the NK cell molecular program $[32,33]$. In addition, studies have suggested that specialized NK cell effector functions (i.e., IFN- $\gamma$, perforin, and granzymes) are controlled, at least in part, at the posttranscriptional level $[14,34]$. Recently, the posttranscriptional mechanisms operative in NK cell have begun to be unraveled, and this paper focuses on new studies that implicate miRNAs as important regulators of NK cell biology. As our knowledge of the molecular programs, including miRNAs, that regulate NK cells increases, this will lead to identification of novel molecules and pathways that may be manipulated to enhance or attenuate NK cell function.

\section{MicroRNAs}

MicroRNAs (miRNAs) are a family of hundreds of small, noncoding RNAs that regulate numerous cellular functions primarily by targeting sites in the $3^{\prime}$ UTR of mRNAs thereby suppressing translation or causing mRNA degradation [41]. An alternative mode of action whereby a miRNA increases mRNA translation in stressed cells via binding to the $5^{\prime}$ UTR was reported [42], but it remains unclear whether this applies to other miRNAs. MiRNA genes are present in the genome (with $>1000$ miRNA sequences predicted in humans and mice), transcribed as long primary (pri-miRNA) transcripts that are subsequently "cropped" by the Drosha/Dgcr8 complex into precursor miRNA (pre-miRNA) that have a characteristic stem loop structure [43]. The pre-miRNA is exported to the cytoplasm where it is further processed by the Dicer complex (including Dicer1), yielding mature 1926 nucleotide miRNAs. The mature miRNA is loaded into the RNA-induced silencing complex (RISC) that includes Argonaute proteins and thereby directs down-regulation of protein levels [44-46]. Thus, the mature miRNA is the "business end" of the miRNA gene and is highly relevant to their regulatory function (Figure 1).

MiRNA biogenesis is regulated at multiple levels, and private components have been identified that may control individual miRNA expression levels. Further, many miRNAs exist in families, with closely related members that share key binding specificity sequences, including the "seed" sequence that is one major determinant of target specificity. These families of miRNAs are thought to cooperate in their regulation of target genes, and thus miRNA loss-of-function experiments should account for all expressed family members of a given family. MiRNAs can be computationally predicted to bind to hundreds of target mRNAs, but these predictions are prone to false positive, and negatives, and thus it is critical to biochemically and biologically validate predicted miRNA: messenger RNAs target interactions. In addition, multiple disparate mature miRNAs likely regulate the same mRNA via distinct and/or overlapping $3^{\prime}$ UTR binding sites. MiRNAs classically limit protein translation and thereby influence a broad spectrum of cellular processes, including cell division, survival, trafficking, intracellular signaling, adhesion, and metabolism. Therefore, it is not surprising that miRNA dysregulation has also been consistently linked to malignant transformation $[47,48]$. The precise contribution of these two predominant miRNA repression mechanisms, mRNA degradation versus translational blockade, remains controversial, and it is likely both operate in mammalian cells.

In immunity, the role of miRNA-mediated regulation is well characterized in adaptive $\mathrm{T}$ and $\mathrm{B}$ lymphocytes, where they influence development as well as peripheral functions, clearly supported by mouse models of miRNA gain and loss of function [49]. While miRNA regulation of NK cell function remains a key question in the NK cell field [3], this paper synthesizes recent studies that have provided the first insights into the expressed mouse and human NK cell miRNA transcriptomes and mechanisms whereby miRNAs regulate NK cell development, homeostasis, and functional responses.

\section{MicroRNA Expression by NK Cells}

Several studies have profiled across differing cell types to identify miRNA "signatures" within the hematopoietic system, for example [50-52]. Many of these studies utilized Sanger sequencing of small RNA clones or miRNA microarrays, which offer comparatively less dynamic range of detection and/or limited miRNA interrogation, relative to unbiased next-generation small RNA sequencing approaches. To date, three studies utilizing next-generation sequencing have been reported in mouse and human NK cells. The top 20 expressed miRNAs by human or mouse NK cells from 


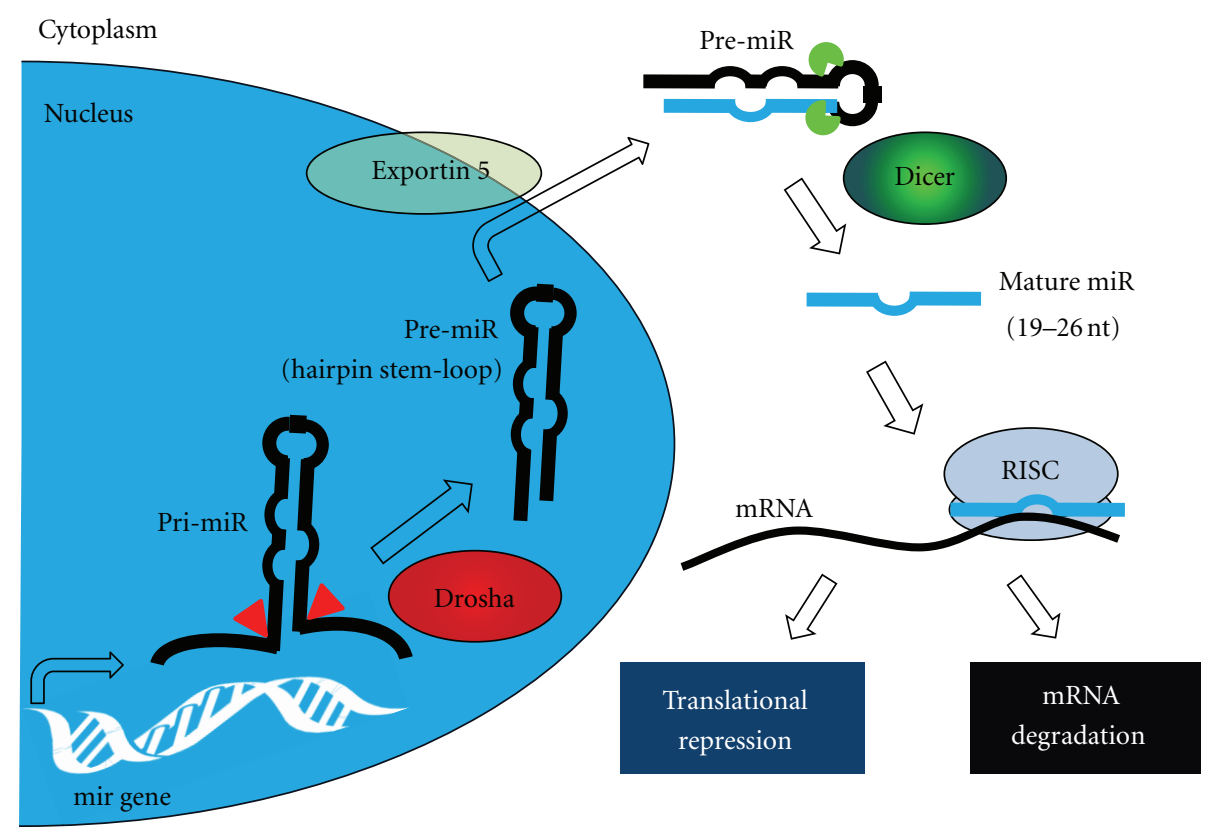

FIGURE 1: Schematic summary of miRNA biogenesis and mechanism of action to inhibit protein translation.

each study are listed in Table 1 . We reported the miRNA transcriptome of resting and IL-15 activated murine splenic NK cells [37]. The miRNA profiles of resting and 24-hour IL-15 activated splenic NK cells were largely similar, confirmed with several orthogonal techniques including Agilent microarrays and RT-qPCR, and the top altered miRNAs are listed in Table 2. Two additional studies sequenced the small RNA compartments of resting and IFN-alpha [35] or IL-2/-15/-21 [36] activated human peripheral blood $\mathrm{CD} 56^{+} \mathrm{CD}^{-} \mathrm{NK}$ cells. While the majority of significantly changed miRNAs in IFN-alpha treated NK cells were down regulated, most miRNAs in IL-2/-15/-21 treated cells were upregulated. These differences may reflect miRNA changes that are specific to the mode of NK cell stimulation or the time frame of measurement. It remains to be resolved why miRNAs ranked in the top 10 in resting NK cells from each study are differentially regulated despite two similar endprocesses cytokine activation. One possible explanation is that profiling from these studies was limited to a single human donor and therefore reflects the biological variation inherent to human NK cells. Other explanations may be technical-differing RNA preparation (which influences small RNA loss during isolation), library construction, sequencing approaches, or bioinformatics issues including normalization.

Thus, there remains a great need in field to report high-quality unbiased miRNA expression analysis including multiple biological replicates in human and mouse NK cells and their developmental and functional subsets, and complete deposition of profiling data in raw formats in public databases to promote cross-study comparisons. For example, do CD56 $6^{\text {bright }}$ and CD56 ${ }^{\text {dim }}$ human NK cells express different miRNAs? Do CD56 ${ }^{\mathrm{dim}} \mathrm{NK}$ cell subsets with functional differences based on CD94, NKG2A, or CD57 differ in their miRNA profiles? Do mouse NK cells at different stages of maturation and function based on CD27 and CDllb, thymic versus splenic NK cells, and differing stages of NK cell developmental intermediates express similar miRNAs? Further, priming and activation results in profound changes in NK cell functionality, and stimulation through different receptors (cytokine receptors, activating NK cell receptors, adhesion molecules) may differentially alter miRNA expression. Do NK cell miRNA profiles differ during viral infection, licensed versus unlicensed state, or naïve versus memory/ memory-like NK cells? Additional work will also be needed to fully understand how changes in miRNA levels are mechanistically induced, their time courses of alteration, and how physiologic changes influence their targeted mRNA.

\section{Impact of Global MicroRNA Alteration in NK Cells}

A large repertoire of mature miRNAs is expressed by NK cells [37], which depend on processing enzymes including Drosha/DGCR8 and Dicer1 (Figure 1). Thus, knockout of critical miRNA processing genes, resulting in the "global loss" of mature miRNA expression, has been used to reveal whether miRNA regulation per se is important for a cell lineage's development and/or function. The first functional studies of miRNA in lymphocytes utilized Dicer1 knockout mice to eliminate all Dicer1-dependent miRNAs and were focused on $\mathrm{T}$ cells $[53,54]$. These studies found that global reductions of mature miRNA led to increased IFN- $\gamma$ production and activation, with a severe loss of cell numbers and proliferation. Similarly, more recent studies focused on NK cells have reported comparable results (Table 3 ), with a few notable differences. 
TABLE 1: Top expressed miRNAs in three studies, detected and enumerated by small RNA Illumina sequencing of resting human $\mathrm{CD}^{2} 6^{+} \mathrm{CD}^{-}$ human $[35,36]$ or NK1.1 $1^{+} \mathrm{CD}^{-}$murine [37] NK cells. The Wang et al. data is limited to the 12 miRNAs reported in the published paper, since the data was not provided in supplemental files nor deposited in public databases.

\begin{tabular}{lccc}
\hline Rank & Wang, 2012 (human) [35] & Liu, 2012 (human) [36] & Fehniger, 2010 (mouse) [37] \\
\hline 1 & hsa-miR-21 & hsa-let-7f & mmu-miR-21 \\
2 & hsa-let-7f & hsa -let-7g & mmu-miR-16 \\
3 & hsa-let-7a & hsa-let-7a & mmu-miR-142-5p \\
4 & hsa-miR-140-3p & hsa-miR-423-5p & mmu-miR-142-3p \\
5 & hsa-miR-146b-5p & hsa-miR-140-3p & mmu-miR-24 \\
6 & hsa-let-7g & hsa-miR-320a & mmu-miR-29a \\
7 & hsa-miR-142-3p & hsa-let-7b & mmu-miR-26a \\
8 & hsa-miR-101 & hsa-let-7i & mmu-miR-150 \\
9 & hsa-miR-378 & hsa-miR-29a & mmu-let-7f \\
10 & hsa-let-7b & hsa-miR-103 & mmu-let-7g \\
11 & hsa-miR-103 & hsa-miR-101 & mmu-miR-22 \\
12 & hsa-miR-30e & hsa-miR-142-5p & mmu-miR-29b \\
13 & & hsa-miR-21 & mmu-miR-26b \\
14 & & hsa-miR-107 & mmu-let-7a \\
15 & & hsa-miR-192 & mmu-let-7c \\
16 & & hsa-miR-185 & mmu-miR-20a \\
18 & & hsa-miR-26b & mmu-miR-15a \\
19 & & hsa-let-7d & mmu-miR-342-3p \\
20 & & hsa-miR-320b & mmu-let-7i \\
\end{tabular}

TABLE 2: Selected up- or down-regulated miRNAs during cytokine activation of NK cells. miRNAs were selected based on the following criteria: top three fold change within the top 12 expressed miRNAs [35], significant miRNAs consistently changed by the listed stimulation [36], and top three fold change [37].

\begin{tabular}{|c|c|c|c|}
\hline & Wang, 2012 (human) [35] & Liu, 2012 (human) [36] & Fehniger, 2010 (mouse) [37] \\
\hline Stimulation & IFN- $\alpha$ & IL-2, IL-15, or IL-21 & IL-15 \\
\hline Duration & 12 or 24 hours & 36 hours & 24 hours \\
\hline Up-regulated & hsa-let-7b & $\begin{array}{l}\text { hsa-miR-155 } \\
\text { hsa-miR-15a }\end{array}$ & $\begin{array}{l}\text { mmu-miR-188-5p } \\
\text { mmu-miR-339-5p } \\
\text { mmu-miR-19a }\end{array}$ \\
\hline Down-regulated & $\begin{array}{l}\text { hsa-miR-378 } \\
\text { hsa-miR-103 } \\
\text { hsa-miR-30e }\end{array}$ & $\begin{array}{l}\text { hsa-miR-1246 } \\
\text { hsa-miR-331-3p }\end{array}$ & $\begin{array}{l}\text { mmu-miR-223 } \\
\text { mmu-miR-26b } \\
\text { mmu-miR-181a }\end{array}$ \\
\hline
\end{tabular}

Bezman et al. used an inducible (estrogen receptor, ER) Cre model combined with LoxP-flanked Dicer1 and DGCR8 alleles to eliminate miRNAs in all cells in the mouse following tamoxifen treatment [38]. Narrowing their focus to the impact of this miRNA loss on NK cells, this study showed increased NK cell apoptosis in the periphery, combined with a selective loss of more mature CD11b CD27 NK cells, as well as reduction in surface expression of the activating NK cell receptor NKG2D. These findings were coupled with reduced IFN- $\gamma$ production and degranulation (CD107a surface expression) following stimulation with anti-NK1.1, antiLy49H, and anti-NKp46, but not stimulation with cytokines such as IL-12 and IL-18. The authors concluded that miRNAs are essential regulators of NK cell development and ITAMbased stimulation of NK cells. In addition, miRNA-deficient Ly $49 \mathrm{H}^{+} \mathrm{NK}$ cells robustly proliferated in response to MCMV infection, but did not survive, and thus were not able to mount an effective NK cell MCMV response. However, these results may have complex interpretations influenced by NK cell extrinsic factors, since the utilized model resulted in global mature miRNA loss in all cells in the organism.

Our laboratory utilized a more specific Cre model to investigate the results of Dicer1-depenedent miRNA loss [39]. We used hCD2-Cre transgenic mice [55], which express 
TABLe 3: Summary of global miRNA-deficient or over-expression (Eri1 ${ }^{-/-}$) NK cells. ${ }^{*}$ In particular, at latest stages of NK cell maturation. ${ }^{* *}$ In response to activating (ITAM) receptor-mediated stimulation.

\begin{tabular}{|c|c|c|c|}
\hline & Bezman et al. [38] & Sullivan et al. [39] & Thomas et al. [40] \\
\hline Cre Model & ER-Cre & hCD2-Cre & Global Knockout \\
\hline Gene & Dicer $^{\mathrm{fl} / \mathrm{fl}} / \mathrm{DGCR} 8^{\mathrm{fl} / \mathrm{fl}}$ & Dicer $^{\mathrm{f} / \mathrm{fl}}$ & Eril $^{-/-}$ \\
\hline Effect on miRNAs & $\downarrow$ & $\downarrow$ & $\uparrow$ \\
\hline Proliferation & $\downarrow$ & $\downarrow$ & $\downarrow$ \\
\hline \# NK Cells & $\downarrow *$ & $\downarrow *$ & $\downarrow *$ \\
\hline Survival & $\downarrow$ & $\downarrow$ & $\leftrightarrow$ \\
\hline IFN- $\gamma$ production & $\downarrow * *$ & $\uparrow$ & $\downarrow^{* *}$ \\
\hline $\begin{array}{l}\text { Degranulation } \\
\text { (CD107a) }\end{array}$ & $\downarrow$ & $\uparrow$ & $\leftrightarrow$ \\
\hline $\begin{array}{l}\text { Receptor Repertoire } \\
\text { Alterations }\end{array}$ & \NKG2D & None Observed & $\begin{array}{l}\text { Multiple, especially } \\
\text { เLy49H/D }\end{array}$ \\
\hline MCMV Response & $\begin{array}{c}\leftrightarrow \text { IFN- } \gamma \text { production } \\
\downarrow \text { Ly } 49 \mathrm{H}^{+} \text {NK Cells }\end{array}$ & $\uparrow I F N-\gamma$ Production & $\begin{array}{c}\leftrightarrow \mathrm{IFN}-\gamma \text { production } \\
\downarrow \mathrm{Ly} 49 \mathrm{H}^{+} \text {NK Cells }\end{array}$ \\
\hline In vitro Cytotoxicity & Not reported & Not reported & $\leftrightarrow$ \\
\hline
\end{tabular}

Cre from the early stages of NK cell development in the bone marrow, shown by crossing with a Rosa26-LoxP-STOPLoxP-YFP knock-in reporter mouse [39]. Thus, in these experiments Dicer1 was removed from NK cells (marked by concurrent YFP expression) during the earliest stages of development, in contrast to eliminating Dicer1 from mature peripheral NK cells at various stages of development or maturation. Additionally, the hCD2-Cre transgene was expressed in a lymphocyte restricted manner, and, while not completely NK cell specific $[56,57]$, removes many potential confounders by providing Dicer1-competent hematopoietic and non-hematopoietic cells, except for lymphocytes. This model confirmed the reduced numbers and percentages of NK cells, and reduced in vitro survival and proliferation, indicating that $\mathrm{NK}$ cell development and homeostasis are critically regulated by miRNAs. However, in the hCD2Cre mice, NK cells produced increased IFN- $\gamma$ and had enhanced degranulation (CD107a surface expression) in response to multiple activating stimuli, which contrasted with the hypofunctionality reported in the induced wholemouse miRNA loss model [38]. Further, these findings in $\mathrm{hCD} 2$-Cre mice were corroborated by increased IFN- $\gamma$ production by NK cells in vivo during MCMV infection, which was also evident in mice heterozygous for the LoxPflanked Dicer1 allele. Recently, NK cell-specific Cre models have been reported driven by NKp46/Ncr1 promoters in a BAC transgenic [56], or NKp46/Ncr1 by knock-in [57]. Thus, the tools are now available to definitively evaluate both global and specific miRNA loss and gain of function in NK cells, without confounders from other cell types.

Another study by Thomas et al. [40] focused on Eril, a highly conserved exoribonuclease that is involved in $5.8 \mathrm{~S}$ rRNA $3^{\prime}$ end processing and a negative regulator of global miRNA abundance. The authors found that Eri1-deficient $\mathrm{NK}$ and $\mathrm{T}$ cells displayed an increase in global miRNA abundance. NK cells seemed particularly susceptible to the effects of Eril loss and displayed decreased percentage and numbers, especially at the latest stages of development. The Eri1-deficient NK cells displayed an altered cell receptor repertoire, including altered $\mathrm{Ly} 49 \mathrm{H}$ expression. In addition, while Eri1 ${ }^{-1-}$ NK cells did not show a defect in IFN- $\gamma$ production in response to IL-12 and IL-18, they produced less IFN- $\gamma$ in response to ITAM-dependent activating receptors. Eril-deficient NK cells also showed a decreased proliferation in response to MCMV infection, with increased viral titers, demonstrating the importance of Eril (probably due to miRNA alterations) in the context of viral infection. While Eri1-deficient NK cells have changes in global miRNA expression and a clear development, maturation and functional phenotype, one caveat to these findings acknowledged by the authors is that other RNA species are affected by Eri1, thereby providing alternative explanations for the NK cell phenotype. Therefore, this study clearly implicates Eri1mediated RNA processing in NK cell development and functional responses, probably reflective of global miRNA changes in NK cells.

Collectively, the preponderance of evidence suggests that miRNAs promote cellular survival, maturation, and proliferation, while suppressing the production of key immune cytokines such as IFN- $\gamma$. However, the study by Thomas et al. suggests that miRNA-influenced genes are perturbed with either global overexpression or repression: increased miRNA expression can also affect NK cell homeostasis, supporting a role of miRNAs as "fine tuners" of cellular homeostasis. The effects of total miRNA elimination or increase on specific functions of NK cells, however, are difficult to extricate from effects on survival, and thus studying the cell intrinsic effects of individual miRNAs in NK cells will be a productive approach to identifying specific miRNA effects and their downstream mRNA targets and mechanisms.

\section{MicroRNA Regulation of NK Cell Development}

NK cells originate from hematopoietic stem cells in the bone marrow, and as they mature, they require the expression of a number of signaling proteins and transcription factors 
essential for the NK lineage $[1,5,6,58]$. As noted above, global alteration of miRNAs in NK cells results in perturbed NK cell development; however, little is known about the role of specific miRNA regulation of NK cell development. To date, two miRNAs and their targeted molecules have been implicated in this process: miR-150 targeting c-Myb, and miR-181a/b targeting NEMO-like kinase (NLK).

MiR-150 was first identified as a highly expressed miRNA in the $\mathrm{T}$ and $\mathrm{B}$ lymphocyte lineage, with expression correlating to the degree of cell maturity [59]. In mice, miR-150 expression acts as a fine tuner of B cell production through the targeting of c-Myb, a transcription factor with multiple roles in hematopoiesis $[60,61]$. The role of this miRNA in regulating $\mathrm{T}$ cells is less clear, since miR-150 overexpression only modestly reduces mature $\mathrm{T}$ cell numbers, in part through c-Myb. Notch3, a receptor important to thymocyte differentiation is another possible target of miR-150 [62]. The Lanier group reported that $\mathrm{miR}-150^{-/-}$mice have a deficiency of mature NK cells resulting from defects in maturation and proliferation [63]. Furthermore, mature NK cells from miR-150-/- mice produce less IFN- $\gamma$ upon cytokine stimulation. The authors suggest that, as in B and $\mathrm{T}$ lymphocytes, miR-150 likely regulates NK development through targeting $\mathrm{c}-\mathrm{Myb}$, since $\mathrm{c}-\mathrm{Myb}^{+/-}$heterozygous mice phenocopy the miR-150-/- NK cell phenotype. This is the first example of miRNA regulating a key transcription factor thereby regulating NK cell development and maturation.

Like miR-150, two miR-181 family members, miR-181a and miR-181b, are also expressed in lymphocytes in a stagespecific manner. Ectopic expression in murine models results in increased B cell [64] and T cell numbers [65]. Using an in vitro NK cell differentiation system, Cichocki et al. demonstrated that miR-181 expression increases in parallel with the maturation stages of human NK cells. Further, overexpression of miR-181a or miR-181b in CD34 ${ }^{+}$progenitor cells that are cultured in vitro in $\mathrm{NK}$ cell differentiation conditions results in an increased output of $\mathrm{CD} 56{ }^{+} \mathrm{CD} 3$ NK cells [66]. In this study, miR-181 was shown to target NLK, a negative regulator of the Notch pathway, which is essential for lymphocyte development. Notch signals have been shown to support in vitro human NK cell differentiation [67-69], and this work demonstrates a role for miR-181 family members in regulating NK cell development, possibly through modulating NLK and Notch in lymphoid or NK cell progenitors.

\section{MicroRNA Regulation of NK Cell Function}

The production of IFN- $\gamma$, a key immune cytokine produced in abundance by activated NK cells, is complex and involves the integration of multiple signaling pathways [8] and multiple layers of regulation [70]. In terms of posttranscriptional regulation, studies have previously indicated a role for a $5^{\prime}$ psuedoknot and $3^{\prime}$ AU-rich elements in the stability of the IFN- $\gamma$ transcript [71], and miRNA-mediated regulation has also recently been reported. As discussed previously, the effect of Dicer1 elimination in T cells and NK cells is to increase IFN- $\gamma$ production $[39,53,54]$, demonstrating that IFN- $\gamma$ is a target (whether direct or indirect) of
Dicer1-dependent miRNAs. While many miRNAs have been proposed to alter IFN- $\gamma$ production, these effects may be due to suppression of upstream signaling components. For example, miR-181a/b was linked to indirect human NK cell IFN- $\gamma$ regulation, with overexpression using lentivirus based approaches reported to increase IL-12-plus IL-18-induced IFN- $\gamma$ production following 14-day culture in IL-15 [66]. In addition, STAT4, a key mediator of IL-12-induced signals, was reported to be targeted by miR-132, 212, and 200a [72]. Several miRNAs, including the miR 17 92 cluster are expressed in NK cells [37], and have been shown to regulate IFN- $\gamma$ in $\mathrm{T}$ cells [73]. Further study of such candidate miRNAs in NK cells is warranted, since mRNA targets may differ between these two distinct cell lineages. Three miRNA families have been found to specifically target IFN- $\gamma$ or genes immediately upstream of its induction: miR-29, miR-155, and miR-15/16 (Figure 2).

MiR-29 demonstrates modest expression in resting NK cells [37], and has been shown to regulate the IFN- $\gamma$ pathway by two independent laboratories $[74,75]$. However, these studies report somewhat differing mechanisms of regulation based on proposed miR-29 targets. Ma et al. showed a direct regulation of IFN- $\gamma$ in $\mathrm{NK}$ and $\mathrm{T}$ cells, and used an in vivo sponge model targeting miR-29 resulting in increased IFN- $\gamma$ protein production [74]. In contrast, Steiner et al. showed, in $\mathrm{CD}^{+} \mathrm{T}$ cells, an indirect regulation of T-bet and Eomes, two important transcription factors that induce IFN- $\gamma$ mRNA, but no direct regulation of IFN- $\gamma$ mRNA by miR-29 [75]. Additional in vitro studies by our lab in 293T cells utilizing luciferase sensor-plasmids failed to identify the murine IFN$\gamma 3^{\prime}$ UTR as a direct target of miR-29 [39]. Further study will be required to clarify the precise role of miR-29 in IFN- $\gamma$ regulation in NK cells using NK cell-specific genetic models.

MiR-155, the miRNA product of the BIC non-coding RNA, has been previously shown to play a role in B [7679], T cell [80, 81], dendritic cell [82], and macrophage [83] biology. While miR-155 is modestly expressed in resting mouse and human NK cells, it has markedly increased expression following combined cytokine activation with IL12 plus IL-18, peaking at 24 hours ([37, 84] and Leong, Sullivan, and Fehniger; unpublished data). MiR-155 is not predicted to directly target the human or mouse IFN- $\gamma$ 3'UTR. Trotta and colleagues have reported miR-155 as a positive regulator of IFN- $\gamma$ production from mature human NK cells following IL-12 plus IL-18 activation, through repression of SHIP-1 [85], an established negative regulator of PI3 K-induced IFN- $\gamma$ production [84]. Additional studies evaluating miR-155 in the context of in vivo infection and tumor models will help to clarify the relative importance of miR-155 induction on NK cell responses in vivo. In addition, it is likely that miR-155 targets additional mRNAs during activation, that regulate the $\mathrm{NK}$ cell activation program. Thus, while miR-155 has a clear role in regulating IFN- $\gamma$ production and targets SHIP-1, it likely has pleiotropic effects, controlling different aspects of NK cell homeostasis and effector function.

The miR-15/16 family is encoded from two distinct loci in the genome, miR-15a/16-1 and miR-15b/16-2, which are processed to miR-15a, miR-15b, and miR-16 mature 


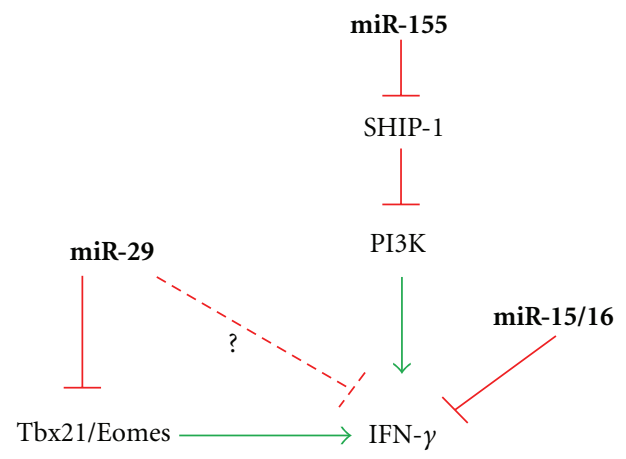

FIgURE 2: Summary of known miRNA interactions regulating IFN- $\gamma$ or immediate upstream signals that induce IFN- $\gamma$ in NK cells.

miRNAs. This family has been shown to regulate cell survival $(\mathrm{Bcl} 2)$, cell cycle (cyclin D1), and has been implicated in the development or progression of several malignancies, including chronic lymphocytic leukemia [86, 87]. Mir-15a, 15b, and 16 are among the most abundantly expressed miRNAs in NK cells, suggesting that transcription of both loci is operative [37]. These family members are computationally predicted to target the murine IFN $-\gamma 3^{\prime} \mathrm{UTR}$, which has been confirmed in vitro by luciferase sensor-plasmid experiments [39]. Moreover, mature miRNAs from this family are down regulated in primary NK cells after cytokine activation. While these findings suggest that the miR-15/16 family of miRNAs may be key players in regulating NK cell IFN- $\gamma$ production, additional studies utilizing in vitro and in vivo loss- and gainof-function will be required to define the non-redundant role of these miRNAs on NK cell IFN- $\gamma$ production.

Work on miRNAs regulating cytotoxicity has focused on the two major granule proteins, granzyme B (GzmB) and perforin (Prf1). Our work first identified that both GzmB and Prf1 transcript was readily produced in resting murine NK cells, and was only modestly up regulated following IL-15 activation [14]. However, protein levels and cytotoxic capacity increased dramatically during activation, suggesting a post-transcriptional mechanism of regulation. As one potential candidate for GzmB regulation, miR-223 was identified as the most down-regulated miRNA following IL-15 treatment and directly targets the murine GzmB 3' UTR [37]. However, NK cells from miRNA-223-/- mice [88] appear to express similar amounts of GzmB as wild type mice at baseline, and exhibit levels of cytotoxicity similar to wild type controls, suggesting that miR-223 alone does not play a nonredundant role in limiting murine GzmB translation in resting mouse NK cells (Leong and Fehniger, unpublished data). Additional studies are still needed to determine the ramifications of miR-223 gain- and loss-offunction, in combination with other miRNAs, in primary NK cells.

Two recent studies have identified miRNAs regulating GzmB and Prf1 in human NK cells. In the first, Kim et al. demonstrated that miR-27a-5p (miR-27a*) targeted both $3^{\prime}$ UTRs, and using in vitro differentiated NK cells (CD34 ${ }^{+}$ hematopoietic progenitors cultured for several weeks in
NK cell differentiating conditions), observed reduced GzmB and Prf1 protein with miR-27a-5p overexpression in this system [89]. Activation with IL-15 paradoxically leads to up regulation of this miRNA, possibly serving to dampen further GzmB and Prf1 production. Inhibition of miR-27a$5 \mathrm{p}$ in these differentiated NK cells resulted in enhanced in vitro killing and tumor protection in a xenograft model. However, the miRNA and mRNA expression of in vitro differentiated NK cells that require long-term culture to freshly isolated primary human NK cells are an important caveat to these findings. Indeed, miR-27a-5p (miR-27a*) is expressed at very low levels in both mouse [37] and human resting NK cells [36], suggesting a limited role for this miRNA outside of extensive cytokine activation or ex vivo culture. Additional loss-of-function data in primary human NK cells would help support the role of miR-27a-5p in regulating GzmB and Prf1.

In contrast to the rheostat model of miR-27a-5p, mature miR-378 and miR-30e expression is reduced upon IFN- $\alpha$ stimulation, releasing repression of GzmB and Prf1 [35]. Expression of both miRNAs was shown to be inversely correlated with GzmB and Prf1 protein production. Further, nucleofection of miRNA sponges against either miRNA-378 or miR-30e in NK-92 cells leads to enhanced cytotoxicity against K562 tumor targets. In another study using the human NKL cell line, stimulation through NKG2D led to downregulation of a number of miRNAs [90]. One of these miRNAs, miR-30c-1-3p (miR-30c- $\left.{ }^{*}\right)$ was shown to target HMBOX1, an inhibitory transcription factor of cytokine secretion. Overexpression or inhibition of miR-30c-1-3p resulted in altered killing against two hepatoma cell lines, again with caveat that additional validation using primary NK cells is needed. Collectively, these studies provide evidence that cytotoxic effector molecules, including GzmB and Prf1, are controlled by miRNAs in NK cells. Since differences in $3^{\prime}$ UTRs exist between human and mouse granzyme B and perforin, careful evaluation of each candidate miRNA in both species will be required to fully understand their roles in regulating NK cell cytotoxicity.

\section{Target Cell MicroRNAs: Regulation of NK Cell Recognition}

NK cell recognition of virus-infected and tumor targets depend on a complex interplay between signals from activating and inhibitory NK cell receptors $[2,10]$. NKG2D is one of the best characterized activating NK cell receptors with ligands that are up regulated in the setting of viral infection or genotoxic stress $[91,92]$. The Mandelboim lab was the first to demonstrate that one human NKG2D ligand, MICB, was directly targeted by a miRNA encoded by the human CMV virus, hcv-miR-UL112-1. This resulted in decreased binding of NKG2D on NK cells to virus-infected cells, as well as reduced NK cell mediated cytotoxicity, suggesting that the viral miRNA was an immune evasion utilizing the target cell's RISC apparatus [93]. Similar virally-encoded miRNAs that target and thereby down-regulate MICB expression were described in other herpesviruses, including Kaposi's sarcoma-associated herpesvirus (KHSV) and Epstein-Barr 
virus (EBV) [94]. These studies also led to examination of endogenous cellular miRNAs as regulators of NKG2D ligand expression (i.e., miRs-20a, 93, 106b, 372, 373, and 520d), which were shown to directly target MICA and MICB. In vitro overexpression of a pool of these miRNAs resulted in decreased MICA/MICB expression, and in turn blunted NKG2D-based NK cell recognition, suggesting miRNAs as a "tuning" mechanism for NKG2D ligand expression, that may be relevant for cancer cell immunoevasion [95]. Thus, both cellular and virally-encoded miRNAs influence NK cell responses in a cell extrinsic fashion via altering activating NK cell receptor ligand expression. While not yet reported, it seems reasonable to speculate that this mode of NK cell receptor ligand regulation by target cells may extend to other key cell surface receptor ligands required for effective NK cell triggering.

\section{MicroRNA Dysregulation in NK Cell Malignancies}

NK cell malignancies arise in different forms, varying from a chronic NK cell lymphocytosis, more aggressive nasaltype NK/T cell lymphomas, to rapidly progressing, highly aggressive NK cell leukemia/lymphoma [96-98]. Patients with NK cell cancers are rare, and to date only limited mouse models mimicking the disease have been available [99, 100], hampering mechanistic studies of the molecular events important for transformation and progression. Alterations in miRNA expression through varying mechanisms, as well as somatic mutation, have been reported in patients with hematologic malignancies, as well as animal models of other lymphoid cancers [48, 87]. Several reports have now examined the expression of miRNAs in NK cell cancers, primarily nasal-type T/NK lymphomas. Yamanaka and colleagues [31] reported aberrant overexpression of miR-21 and/or miR-155 in malignant NK cell lines $(N=10)$ and primary patient samples $(N=10)$. Further, utilizing loss of function approaches in immortalized NK cell lines derived from patients with NK malignancies, the authors linked pathologic overexpression of miR-21 with targeting and decreased expression of two tumor suppressors: phosphatase and tensin homolog (PTEN) and programmed cell death 4 (PDCD4). In addition, overexpression of miR-155 was linked with targeting of Src homology-2 domain-containing inositol 5-phophatase 1 (SHIP-1), a negative regulator of the PI3 K-AKT signaling pathway [101]. This study suggests that several miRNAs converge and cooperate in altering common signal pathways in NK cell malignancy, resulting in this case in enhanced AKT signaling and consequent enhanced cell survival, proliferation, and NF- $\kappa \mathrm{B}$ activation (Figure 3 ). Additional studies will be required to determine the frequency and extent of miR-21 and miR-155 overexpression in NK cell cancers, and their correlation with clinical outcomes. $\mathrm{Ng}$ et al. [102] evaluated the prognostic impact of candidate miRNA in a set of 50 extra nodal NK/T cell lymphomas and identified that low relative expression of miR-146a was an independent poor prognostic factor. Further, forced overexpression of miR-146a in NK cell lines inhibited NF$\kappa \mathrm{B}$ signals, suppressed proliferation, induced apoptosis, and enhanced the chemosensitivity of these NK/T cell lines (SNK6, YT). The authors hypothesize that this occurs via miR-146a suppression of TRAF6, which was also downregulated upon forced miR-146a overexpression, and induces downstream NF- $\kappa$ B signals. For patients with low miR-146a, this would result the loss of a normally present negative feedback loop mediated by miR-146a (Figure 3). A third study by $\mathrm{Ng}$ and colleagues evaluated nasal-type NK/T lymphomas ( $n=30)$ for alteration in candidate miRNA expression using miRNA microarrays, and concluded that miRNAs are predominantly down-regulated, including miR-101, 26a/b, 28-5p, 363, and 146a, compared to non-malignant peripheral blood NK cells [102]. This study identified an 11-fold (NK cell lines) and 2-fold (primary NK tumors) increase in miR155, compared to normal donor $\mathrm{CD}^{+} 6^{+} \mathrm{CD}^{-} \mathrm{NK}$ cells, and no alteration in miR-21 was reported. This suggests that miR-155 and miR-21 overexpression may be variably dysregulated in patients with these malignancies, or that differing technical approaches may bias miRNA profiling study findings, highlighting again the need for consistent normalization approaches and validation of results using secondary, orthogonal miRNA detection techniques. The authors identify correlations between deregulated miRNAs and overexpression of IRF4, BLIMP1, and STMN1 in primary samples, although these have not yet been confirmed using gain or loss of function studies. For each of these candidate miRNAs, it will be important in future studies to support the potential for oncogenic activity by investigating model organisms using genetic gain or loss of candidate miRNA function, restricted to the NK cell compartment. Further, if these miRNA alterations appear to causally contribute to pathogenesis or progression, they may be potentially targeted using miRNA antagomiRs or mimics in vivo.

There is a strong association between infection with Epstein-Barr virus (EBV) and a subset of NK/T cell leukemia/lymphomas, with many associated with direct EBV infection and a type 2 latency program. Ramakrishnan et al. profiled such NK cell lymphoma cell lines, and identified EBV encoded miRNAs that were abundantly expressed [103]. In vitro loss of function of several EBV-miRs (BART7, 9, $17-5 p)$ resulted in reduced cell division rates in some, but not all, immortalized NK cell lines without affecting cell viability. In vitro studies also showed that EBV-miR-BART9 had a positive correlation with the latency protein LMP-1 in these cell lines, using overexpression and knock-down in vitro. These results, while intriguing, require confirmation in additional NK cell lines, and primary malignancy samples. In addition, further studies will be required to fully evaluate the functional impact and importance of EBV-encoded miRNAs in NK tumor cells infected with EBV.

\section{Conclusions}

MiRNAs represent a relatively recently discovered, but highly important, post-transcriptional mode of gene regulation in NK cells. Studies have started to define the expression of mature miRNAs in human and mouse NK cells, identified the importance of miRNAs in NK cell biology in 

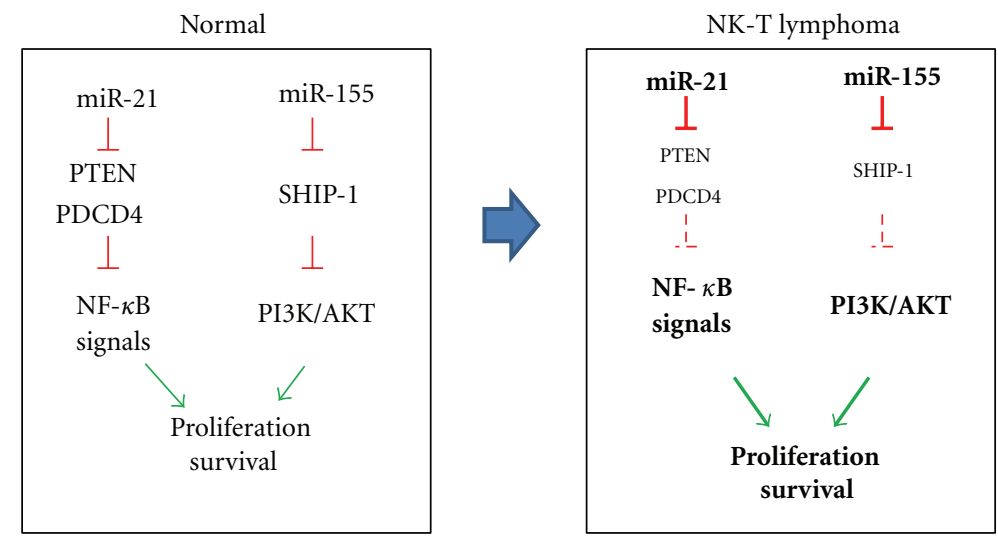

(a)
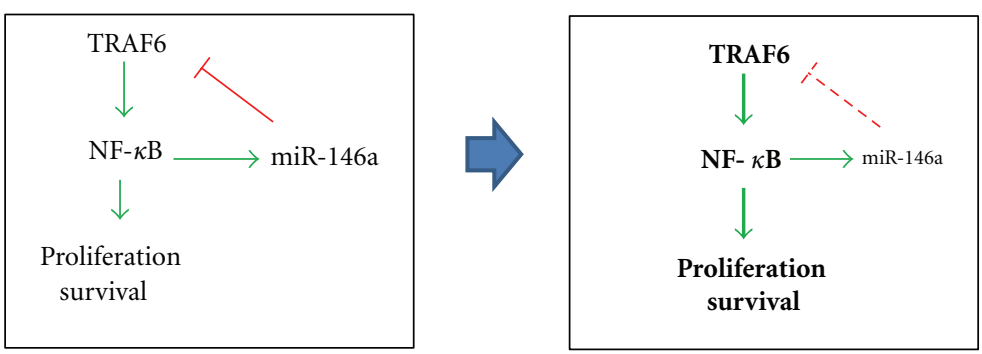

(b)

FIGURE 3: Summary of miRNA alterations identified in NK/T malignancies and proposed mechanisms of altering cell growth and survival. (a) Increased miR-21 and miR-155 was identified in malignant cases by Yamanaka et al. [31]. (b) Decreased miR-146a were identified in malignant cases by Paik et al.

models of global gain or loss of miRNAs, and advanced our understanding of the complex mechanisms whereby individual miRNAs target specific mRNAs to influence the NK cell molecular program. With over 60 highly expressed miRNAs detected in NK cells, it is now critical to investigate their targets and functional impact in all areas of NK cell development and function.

\section{References}

[1] W. M. Yokoyama, S. Kim, and A. R. French, "The dynamic life of natural killer cells," Annual Review of Immunology, vol. 22, no. 11, pp. 405-429, 2004.

[2] L. L. Lanier, "Up on the tightrope: natural killer cell activation and inhibition," Nature Immunology, vol. 9, no. 5, pp. 495-502, 2008.

[3] J. P. di Santo, "Natural killer cells: diversity in search of a niche," Nature Immunology, vol. 9, no. 5, pp. 473-475, 2008.

[4] M. A. Caligiuri, "Human natural killer cells," Blood, vol. 112, no. 3, pp. 461-469, 2008.

[5] A. G. Freud and M. A. Caligiuri, "Human natural killer cell development," Immunological Reviews, vol. 214, no. 1, pp. 56-72, 2006

[6] F. Colucci, M. A. Caligiuri, and J. P. di Santo, "What does it take to make a natural killer?" Nature Reviews Immunology, vol. 3, no. 5, pp. 413-425, 2003.

[7] L. Chiossone, J. Chaix, N. Fuseri, C. Roth, E. Vivier, and T. Walzer, "Maturation of mouse NK cells is a 4-stage developmental program," Blood, vol. 113, no. 22, pp. 54885496, 2009.

[8] E. Vivier, E. Tomasello, M. Baratin, T. Walzer, and S. Ugolini, "Functions of natural killer cells," Nature Immunology, vol. 9, no. 5, pp. 503-510, 2008.

[9] A. H. Jonsson and W. M. Yokoyama, "Chapter 2 natural killer cell tolerance. Licensing and other mechanisms," Advances in Immunology, vol. 101, pp. 27-79, 2009.

[10] N. T. Joncker and D. H. Raulet, "Regulation of NK cell responsiveness to achieve self-tolerance and maximal responses to diseased target cells," Immunological Reviews, vol. 224, no. 1, pp. 85-97, 2008.

[11] L. L. Lanier, "NK cell recognition," Annual Review of Immunology, vol. 23, pp. 225-274, 2005.

[12] Y. T. Bryceson and E. O. Long, "Line of attack: NK cell specificity and integration of signals," Current Opinion in Immunology, vol. 20, no. 3, pp. 344-352, 2008.

[13] S. H. Lee, T. Miyagi, and C. A. Biron, "Keeping NK cells in highly regulated antiviral warfare," Trends in Immunology, vol. 28, no. 6, pp. 252-259, 2007.

[14] T. A. Fehniger, S. F. Cai, X. Cao et al., "Acquisition of murine NK cell cytotoxicity requires the translation of a pre-existing pool of Granzyme B and perforin mRNAs," Immunity, vol. 26, no. 6, pp. 798-811, 2007.

[15] M. Lucas, W. Schachterle, K. Oberle, P. Aichele, and A. Diefenbach, "Dendritic cells prime natural killer cells by trans-presenting interleukin 15," Immunity, vol. 26, no. 4, pp. 503-517, 2007. 
[16] J. Chaix, M. S. Tessmer, K. Hoebe et al., "Cutting edge: priming of NK cells by IL-18," Journal of Immunology, vol. 181, no. 3, pp. 1627-1631, 2008.

[17] J. S. Orange, "Human natural killer cell deficiencies," Current Opinion in Allergy and Clinical Immunology, vol. 6, no. 6, pp. 399-409, 2006.

[18] J. S. Orange and Z. K. Ballas, "Natural killer cells in human health and disease," Clinical Immunology, vol. 118, no. 1, pp. 1-10, 2006.

[19] T. W. Kuijpers, P. A. Baars, C. Dantin, M. van den Burg, R. A. W. Van Lier, and E. Roosnek, "Human NK cells can control CMV infection in the absence of T cells," Blood, vol. 112, no. 3, pp. 914-915, 2008.

[20] C. A. Biron and L. Brossay, "NK cells and NKT cells in innate defense against viral infections," Current Opinion in Immunology, vol. 13, no. 4, pp. 458-464, 2001.

[21] S. M. Vidal, S. I. Khakoo, and C. A. Biron, "Natural killer cell responses during viral infections: flexibility and conditioning of innate immunity by experience," Current Opinion in Immunology, vol. 1, no. 6, pp. 497-512, 2011.

[22] S. S. Farag, T. A. Fehniger, L. Ruggeri, A. Velardi, and M. A. Caligiuri, "Natural killer cell receptors: new biology and insights into the graft-versus-leukemia effect," Blood, vol. 100, no. 6, pp. 1935-1947, 2002.

[23] H. G. Ljunggren and K. J. Malmberg, "Prospects for the use of NK cells in immunotherapy of human cancer," Nature Reviews Immunology, vol. 7, no. 5, pp. 329-339, 2007.

[24] J. Wu and L. L. Lanier, "Natural killer cells and cancer," Advances in Cancer Research, vol. 13, no. 7, pp. 731-736, 2010.

[25] A. Velardi, L. Ruggeri, A. Mancusi, F. Aversa, and F. T. Christiansen, "Natural killer cell allorecognition of missing self in allogeneic hematopoietic transplantation: a tool for immunotherapy of leukemia," Current Opinion in Immunology, vol. 21, no. 5, pp. 525-530, 2009.

[26] K. C. Hsu and B. Dupont, "Natural killer cell receptors: regulating innate immune responses to hematologic malignancy," Seminars in Hematology, vol. 42, no. 2, pp. 91-103, 2005.

[27] K. Imai, S. Matsuyama, S. Miyake, K. Suga, and K. Nakachi, "Natural cytotoxic activity of peripheral-blood lymphocytes and cancer incidence: an 11-year follow-up study of a general population," The Lancet, vol. 356, no. 9244, pp. 1795-1799, 2000.

[28] C. Shuptrine, R. Surana, and L. M. Weiner, "Monoclonal antibodies for the treatment of cancer," Seminars in Cancer Biology, vol. 22, no. 1, pp. 3-13, 2012.

[29] L. Ruggeri, M. Capanni, E. Urbani et al., "Effectiveness of donor natural killer cell aloreactivity in mismatched hematopoietic transplants," Science, vol. 295, no. 5562, pp. 20972100, 2002.

[30] J. S. Miller, Y. Soignier, A. Panoskaltsis-Mortari et al., "Successful adoptive transfer and in vivo expansion of human haploidentical NK cells in patients with cancer," Blood, vol. 105, no. 8, pp. 3051-3057, 2005.

[31] Y. Yamanaka, H. Tagawa, N. Takahashi et al., "Aberrant overexpression of microRNAs activate AKT signaling via down-regulation of tumor suppressors in natural killer-cell lymphoma/leukemia," Blood, vol. 114, no. 15, pp. 3265-3275, 2009.

[32] D. G. T. Hesslein and L. L. Lanier, "Transcriptional control of natural killer cell development and function," Advances in Immunology, vol. 109, pp. 45-85, 2011.
[33] K. Ramirez and B. L. Kee, "Transcriptional regulation of natural killer cell development," Current Opinion in Immunology, vol. 22, no. 2, pp. 193-198, 2010.

[34] D. B. Stetson, M. Mohrs, R. L. Reinhardt et al., "Constitutive cytokine mRNAs mark natural killer (NK) and NK T cells poised for rapid effector function," Journal of Experimental Medicine, vol. 198, no. 7, pp. 1069-1076, 2003.

[35] P. Wang, Y. Gu, Q. Zhang et al., "Identification of resting and type I IFN-activated human NK cell miRNomes reveals microRNA-378 and microRNA-30e as negative regulators of NK cell cytotoxicity," The Journal of Immunology, vol. 189, no. 1, pp. 211-221.

[36] X. Liu, Y. Wang, Q. Sun et al., "Identification of microRNA transcriptome involved in human natural killer cell activation," Immunology Letters, vol. 143, no. 2, pp. 208-217, 2012.

[37] T. A. Fehniger, T. Wylie, E. Germino et al., "Next-generation sequencing identifies the natural killer cell microRNA transcriptome," Genome Research, vol. 20, no. 11, pp. 1590-1604, 2010.

[38] N. A. Bezman, E. Cedars, D. F. Steiner, R. Blelloch, D. G. T. Hesslein, and L. L. Lanier, "Distinct requirements of microRNAs in NK cell activation, survival, and function," Journal of Immunology, vol. 185, no. 7, pp. 3835-3846, 2010.

[39] R. P. Sullivan, J. W. Leong, S. E. Schneider et al., "MicroRNA deficient NK cells exhibit decreased survival but enhanced function," The Journal of Immunology, vol. 188, no. 7, pp. 3019-3030, 2012.

[40] M. F. Thomas, S. Abdul-Wajid, M. Panduro et al., "Eri1 regulates microRNA homeostasis and mouse lymphocyte development and anti-viral function," Blood, vol. 120, no. 1, pp. 130-142, 2012.

[41] L. He and G. J. Hannon, "MicroRNAs: small RNAs with a big role in gene regulation," Nature Reviews Genetics, vol. 5, no. 7, pp. 522-531, 2004.

[42] S. Vasudevan, Y. Tong, and J. A. Steitz, "Switching from repression to activation: microRNAs can up-regulate translation," Science, vol. 318, no. 5858, pp. 1931-1934, 2007.

[43] V. N. Kim, "MicroRNA biogenesis: coordinated cropping and dicing," Nature Reviews Molecular Cell Biology, vol. 6, no. 5, pp. 376-385, 2005.

[44] L. Wu and J. G. Belasco, "Let me count the ways: mechanisms of gene regulation by miRNAs and siRNAs," Molecular Cell, vol. 29, no. 1, pp. 1-7, 2008.

[45] W. Filipowicz, S. N. Bhattacharyya, and N. Sonenberg, "Mechanisms of post-transcriptional regulation by microRNAs: Are the answers in sight?" Nature Reviews Genetics, vol. 9, no. 2, pp. 102-114, 2008.

[46] J. Liu, "Control of protein synthesis and mRNA degradation by microRNAs," Current Opinion in Immunology, vol. 20, no. 2, pp. 214-221, 2008.

[47] A. L. Kasinski and F. J. Slack, "MicroRNAs en route to the clinic: progress in validating and targeting microRNAs for cancer therapy," Nature Reviews Cancer, vol. 11, no. 12, pp. 849-864, 2011.

[48] F. Lovat, N. Valeri, and C. M. Croce, "MicroRNAs in the pathogenesis of cancer," Seminars in Oncology, vol. 38, no. 6, pp. 724-733, 2011.

[49] R. M. O'Connell, D. S. Rao, A. A. Chaudhuri, and D. Baltimore, "Physiological and pathological roles for microRNAs in the immune system," Nature Reviews Immunology, vol. 10, no. 2, pp. 111-122, 2010. 
[50] P. Landgraf, M. Rusu, R. Sheridan et al., "A mammalian microRNA expression atlas based on small RNA library sequencing," Cell, vol. 129, no. 7, pp. 1401-1414, 2007.

[51] R. L. Rossi, G. Rossetti, L. Wenandy et al., "Distinct microRNA signatures in human lymphocyte subsets and enforcement of the naive state in $\mathrm{CD}^{+} \mathrm{T}$ cells by the microRNA miR-125b," Nature Immunology, vol. 12, pp. 796803, 2011.

[52] F. Allantaz, D. T. Cheng, T. Bergauer et al., "Expression profiling of human immune cell subsets identifies miRNAmRNA regulatory relationships correlated with cell type specific expression," PLoS One, vol. 7, no. 1, p. e29979, 2012.

[53] S. A. Muljo, K. M. Ansel, C. Kanellopoulou, D. M. Livingston, A. Rao, and K. Rajewsky, "Aberrant T cell differentiation in the absence of Dicer," Journal of Experimental Medicine, vol. 202, no. 2, pp. 261-269, 2005.

[54] M. M. W. Chong, J. P. Rasmussen, A. Y. Rudensky, and D. R. Littman, "The RNAseIII enzyme Drosha is critical in T cells for preventing lethal inflammatory disease," Journal of Experimental Medicine, vol. 205, no. 10, p. 2449, 2008.

[55] J. de Boer, A. Williams, G. Skavdis et al., "Transgenic mice with hematopoietic and lymphoid specific expression of Cre.," European Journal of Immunology, vol. 33, no. 2, pp. 314-325, 2003.

[56] E. Eckelhart, W. Warsch, E. Zebedin et al., "A novel Ncr1Cre mouse reveals the essential role of STAT5 for NK-cell survival and development," Blood, vol. 117, no. 5, pp. 15651573, 2011.

[57] E. Narni-Mancinelli, J. Chaix, A. Fenis et al., "Fate mapping analysis of lymphoid cells expressing the NKp46 cell surface receptor," Proceedings of the National Academy of Sciences of the United States of America, vol. 108, no. 45, pp. 1832418329, 2011.

[58] J. P. di Santo, "Natural killer cell developmental pathways: a question of balance," Annual Review of Immunology, vol. 24, pp. 257-286, 2006.

[59] S. Monticelli, K. M. Ansel, C. Xiao et al., "MicroRNA profiling of the murine hematopoietic system," Genome biology, vol. 6, no. 8, p. R71, 2005.

[60] B. Zhou, S. Wang, C. Mayr, D. P. Bartel, and H. F. Lodish, "miR-150, a microRNA expressed in mature B and T cells, blocks early B cell development when expressed prematurely," Proceedings of the National Academy of Sciences of the United States of America, vol. 104, no. 17, pp. 7080-7085, 2008.

[61] C. Xiao, D. P. Calado, G. Galler et al., "MiR-150 controls B cell differentiation by targeting the transcription factor c-Myb," Cell, vol. 131, no. 1, pp. 146-159, 2007.

[62] M. Ghisi, A. Corradin, K. Basso et al., "Modulation of microRNA expression in human T-cell development: targeting of NOTCH3 by miR-150," Blood, vol. 117, no. 26, pp. 7053-7062, 2011.

[63] N. A. Bezman, T. Chakraborty, T. Bender, and L. L. Lanier, "miR-150 regulates the development of NK and iNKT cells," The Journal of Experimental Medicine. In press.

[64] C. Z. Chen, L. Li, H. F. Lodish, and D. P. Bartel, "MicroRNAs modulate hematopoietic lineage differentiation," Science, vol. 303, no. 5654, pp. 83-86, 2004.

[65] Q. J. Li, J. Chau, P. J. R. Ebert et al., "miR-181a is an intrinsic modulator of T cell sensitivity and selection," Cell, vol. 129, no. 1, pp. 147-161, 2007.
[66] F. Cichocki, M. Felices, V. McCullar et al., "Cutting Edge: microRNA-181 promotes human NK cell development by regulating notch signaling," The Journal of Immunology, vol. 187, no. 12, pp. 6171-6175, 2011.

[67] V. Bachanova, V. McCullar, T. Lenvik et al., "Activated notch supports development of cytokine producing NK cells which are hyporesponsive and fail to acquire NK cell effector functions," Biology of Blood and Marrow Transplantation, vol. 15, no. 2, pp. 183-194, 2009.

[68] K. Haraguchi, T. Suzuki, N. Koyama et al., "Notch activation induces the generation of functional NK cells from human cord blood CD34-positive cells devoid of IL-15 1," Journal of Immunology, vol. 182, no. 10, pp. 6168-6178, 2009.

[69] R. C. Beck, M. Padival, D. Yeh, J. Ralston, K. R. Cooke, and J. B. Lowe, "The notch ligands jagged2, delta1, and delta4 induce differentiation and expansion of functional human NK cells from $\mathrm{CD} 34^{+}$cord blood hematopoietic progenitor cells," Biology of Blood and Marrow Transplantation, vol. 15, no. 9, pp. 1026-1037, 2009.

[70] H. A. Young, "Regulation of interferon- $\gamma$ gene expression," Journal of Interferon and Cytokine Research, vol. 16, no. 8, pp. 563-568, 1996.

[71] K. S. A. Khabar and H. A. Young, "Post-transcriptional control of the interferon system," Biochimie, vol. 89, no. 6-7, pp. 761-769, 2007.

[72] Y. Huang, Y. Lei, H. Zhang, L. Hou, M. Zhang, and A. I. Dayton, "MicroRNA regulation of STAT4 protein expression: rapid and sensitive modulation of interleukin-12 signaling in human natural killer cells," Blood, pp. 6793-6802, 2011.

[73] S. Jiang, C. Li, V. Olive et al., "Molecular dissection of the miR-17-92 cluster's critical dual roles in promoting Th1 responses and preventing inducible Treg differentiation," Blood, vol. 118, no. 20, pp. 5487-5497, 2011.

[74] F. Ma, S. Xu, X. Liu et al., "The microRNA miR-29 controls innate and adaptive immune responses to intracellular bacterial infection by targeting interferon- $\gamma$," Nature Immunology, vol. 12, pp. 861-869, 2011.

[75] D. F. Steiner, M. F. Thomas, J. K. Hu et al., "MicroRNA29 regulates T-box transcription factors and interferon- $\gamma$ production in helper T cells," Immunity, vol. 35, no. 2, pp. 169-181, 2011.

[76] A. Rodriguez, E. Vigorito, S. Clare et al., "Requirement of bic/microRNA-155 for normal immune function," Science, vol. 316, no. 5824, pp. 608-611, 2007.

[77] T. H. Thai, D. P. Calado, S. Casola et al., "Regulation of the germinal center response by MicroRNA-155," Science, vol. 316, no. 5824, pp. 604-608, 2007.

[78] E. Vigorito, K. L. Perks, C. Abreu-Goodger et al., "microRNA-155 regulates the generation of immunoglobulin class-switched plasma cells," Immunity, vol. 27, no. 6, pp. 847-859, 2007.

[79] G. Teng, P. Hakimpour, P. Landgraf et al., "MicroRNA155 is a negative regulator of activation-induced cytidine deaminase," Immunity, vol. 28, no. 5, pp. 621-629, 2008.

[80] R. M. O'Connell, D. Kahn, W. S. J. Gibson et al., "MicroRNA155 promotes autoimmune inflammation by enhancing inflammatory T cell development," Immunity, vol. 33, no. 4, pp. 607-619, 2010.

[81] S. Kohlhaas, O. A. Garden, C. Scudamore, M. Turner, K. Okkenhaug, and E. Vigorito, "Cutting edge: the Foxp3 target miR-155 contributes to the development of regulatory $\mathrm{T}$ 
cells1," Journal of Immunology, vol. 182, no. 5, pp. 2578-2582, 2009.

[82] C. Lu, X. Huang, X. Zhang et al., "miR-221 and miR-155 regulate human dendritic cell development, apoptosis, and IL-12 production through targeting of p27kip1, KPC1, and SOCS-1," Blood, vol. 117, no. 16, pp. 4293-4303, 2011.

[83] R. M. O’Connell, K. D. Taganov, M. P. Boldin, G. Cheng, and D. Baltimore, "MicroRNA-155 is induced during the macrophage inflammatory response," Proceedings of the National Academy of Sciences of the United States of America, vol. 104, no. 5, pp. 1604-1609, 2007.

[84] R. Trotta, L. Chen, D. Ciarlariello et al., "MiR-155 regulates IFN- $\gamma$ production in natural killer cells," Blood, vol. 119, no. 15, pp. 3478-3485, 2012.

[85] R. M. O'Connell, A. A. Chaudhuri, D. S. Rao, and D. Baltimore, "Inositol phosphatase SHIP1 is a primary target of miR-155," Proceedings of the National Academy of Sciences of the United States of America, vol. 106, no. 17, pp. 7113$7118,2009$.

[86] U. Klein, M. Lia, M. Crespo et al., "The DLEU2/miR-15a/161 cluster controls B cell proliferation and its deletion leads to chronic lymphocytic leukemia," Cancer Cell, vol. 17, no. 1, pp. 28-40, 2010.

[87] M. V. Iorio and C. M. Croce, "MicroRNA dysregulation in cancer: diagnostics, monitoring and therapeutics. A comprehensive review," EMBO Molecular Medicine, vol. 4, no. 3, pp. 143-159, 2012.

[88] J. B. Johnnidis, M. H. Harris, R. T. Wheeler et al., "Regulation of progenitor cell proliferation and granulocyte function by microRNA-223," Nature, vol. 451, no. 7182, pp. 1125-1129, 2008.

[89] T. D. Kim, S. U. H. Lee, S. Yun et al., "Human microRNA27a* targets Prf1 and GzmB expression to regulate NK cell cytotoxicity," Blood, vol. 118, no. 20, pp. 5476-5486, 2011.

[90] J. Gong, R. Liu, R. Zhuang et al., "miR-30c-1* promotes NK cell cytotoxicity against human hepatoma cells via targeting the transcription factor HMBOX1," Cancer Science, vol. 103, no. 4, pp. 645-652, 2012.

[91] S. Gasser, S. Orsulic, E. J. Brown, and D. H. Raulet, “The DNA damage pathway regulates innate immune system ligands of the NKG2D receptor," Nature, vol. 436, no. 7054, pp. $1186-$ 1190, 2005.

[92] M. Champsaur and L. L. Lanier, "Effect of NKG2D ligand expression on host immune responses," Immunological Reviews, vol. 235, no. 1, pp. 267-285, 2010.

[93] N. Stern-Ginossar, N. Elefant, A. Zimmermann et al., "Host immune system gene targeting by a viral miRNA," Science, vol. 317, no. 5836, pp. 376-381, 2007.

[94] D. Nachmani, N. Stern-Ginossar, R. Sarid, and O. Mandelboim, "Diverse herpesvirus microRNAs target the stressinduced immune ligand MICB to escape recognition by natural killer cells," Cell Host and Microbe, vol. 5, no. 4, pp. 376-385, 2009.

[95] N. Stern-Ginossar, C. Gur, M. Biton et al., "Human microRNAs regulate stress-induced immune responses mediated by the receptor NKG2D," Nature Immunology, vol. 9, no. 9, pp. 1065-1073, 2008.

[96] F. Ishida and Y. L. Kwong, "Diagnosis and management of natural killer-cell malignancies," Expert Review of Hematology, vol. 3, no. 5, pp. 593-602, 2010.

[97] R. J. Watters, X. Liu, and T. P. Loughran, "T-cell and natural killer-cell large granular lymphocyte leukemia neoplasias," Leukemia Lymphoma, vol. 52, no. 12, pp. 2217-2225, 2011.
[98] G. Semenzato, F. Marino, and R. Zambello, "State of the art in natural killer cell malignancies," International Journal of Laboratory Hematology, vol. 34, no. 2, pp. 117-128, 2012.

[99] T. A. Fehniger, K. Suzuki, A. Ponnappan et al., "Fatal leukemia in interleukin 15 transgenic mice follows early expansions in natural killer and memory phenotype $\mathrm{CD}^{+}$ T cells," Journal of Experimental Medicine, vol. 193, no. 2, pp. 219-231, 2001.

[100] T. A. Fehniger, K. Suzuki, J. B. van Deusen, M. A. Cooper, A. G. Freud, and M. A. Caligiuri, "Fatal leukemia in interleukin15 transgenic mice," Blood Cells, Molecules, and Diseases, vol. 27, no. 1, pp. 223-230, 2001.

[101] J. H. Paik, J. Y. Jang, Y. K. Jeon et al., "MicroRNA-146a downregulates $\mathrm{NF} \kappa \mathrm{B}$ activity via targeting TRAF6 and functions as a tumor suppressor having strong prognostic implications in NK/T cell lymphoma," Clinical Cancer Research, vol. 17, no. 14, pp. 4761-4771, 2011.

[102] S. B. Ng, J. Yan, G. Huang et al., "Dysregulated microRNAs affect pathways and targets of biologic relevance in nasal-type natural killer/T-cell lymphoma," Blood, vol. 118, no. 18, pp. 4919-4929, 2011.

[103] R. Ramakrishnan, H. Donahue, D. Garcia et al., "EpsteinBarr virus BART9 miRNA modulates LMP1 levels and affects growth rate of nasal NK T cell lymphomas," PloS One, vol. 6, no. 11, Article ID e27271, 2011. 


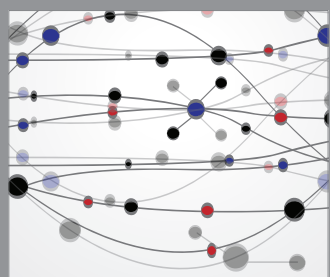

The Scientific World Journal
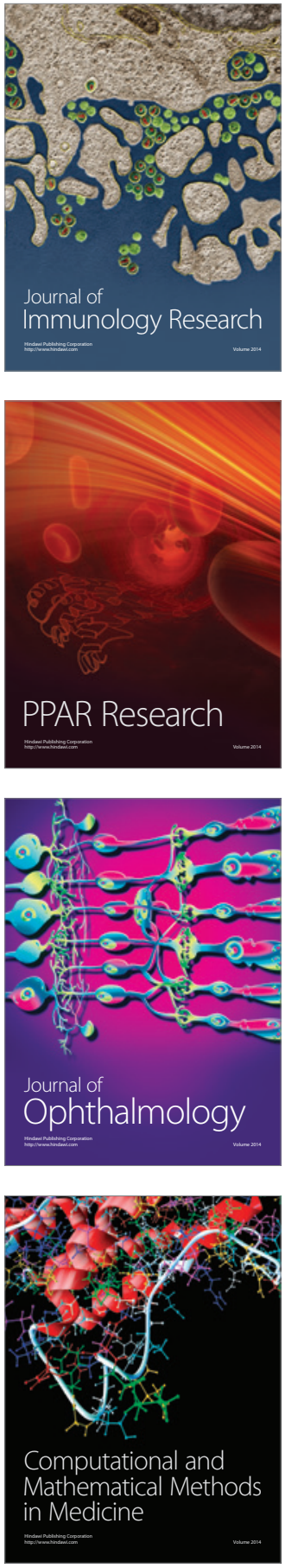

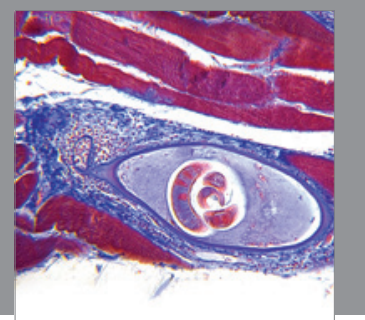

Gastroenterology

Research and Practice
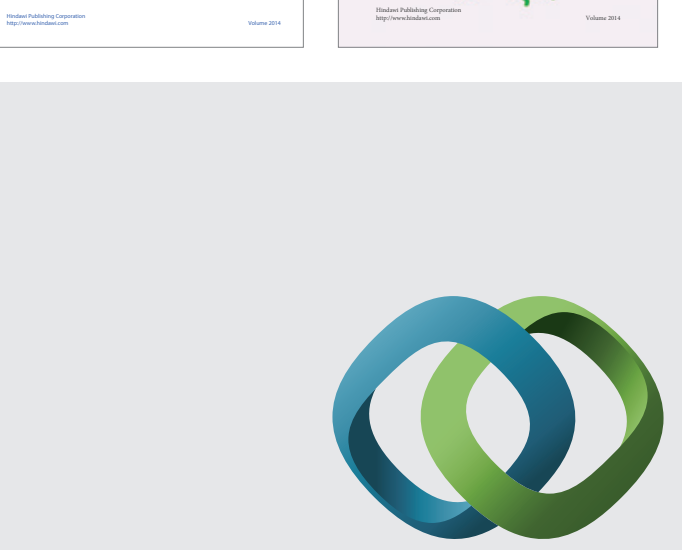

\section{Hindawi}

Submit your manuscripts at

http://www.hindawi.com
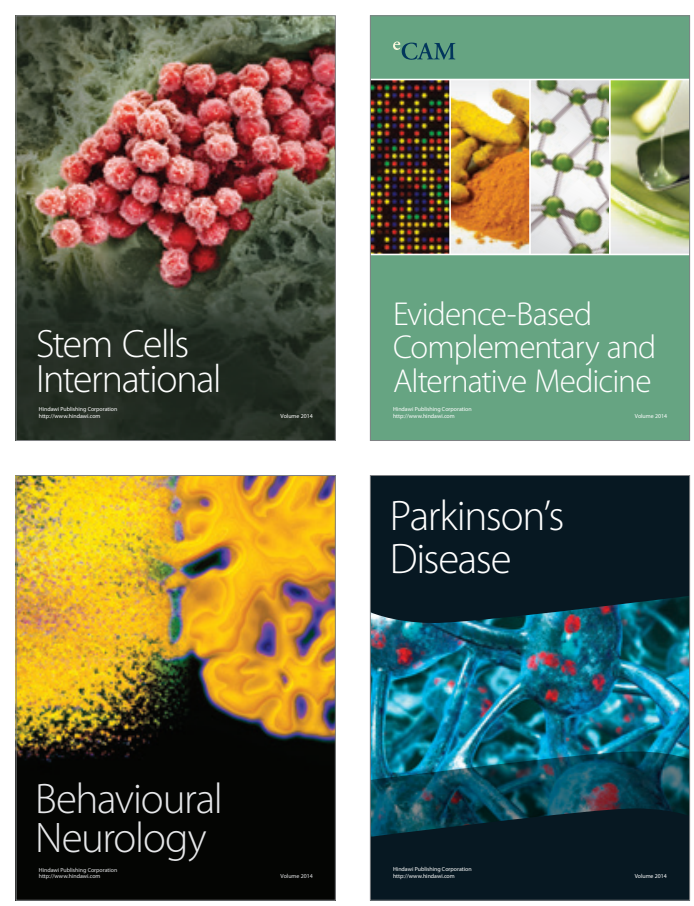

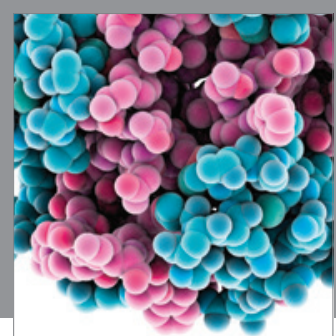

Journal of
Diabetes Research

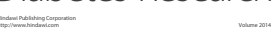

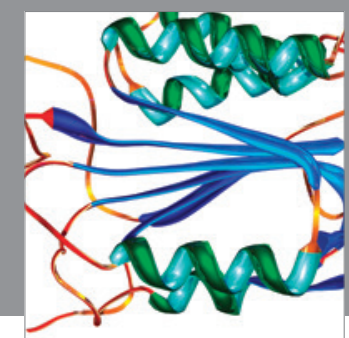

Disease Markers
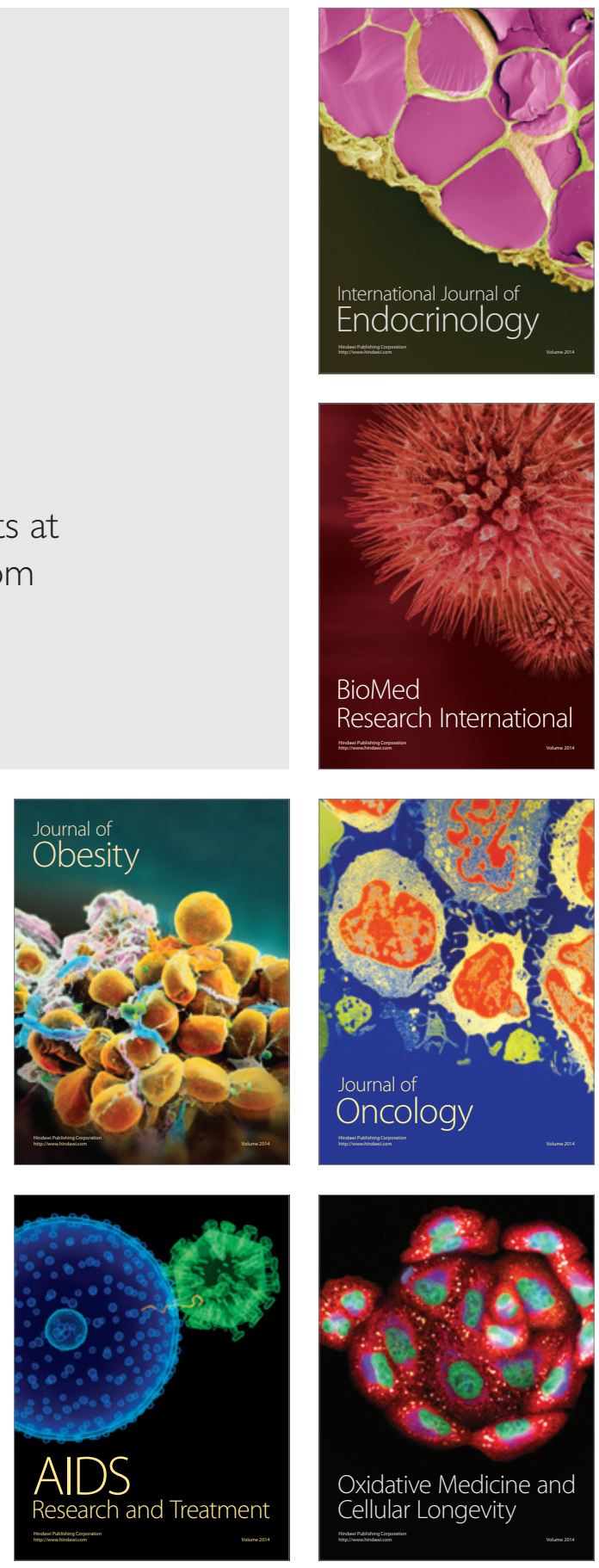